\title{
KARAKTERISTIK KEKUATAN BENDING DAN KEKUATAN TEKAN KOMPOSIT SERAT HYBRID KAPAS/GELAS SEBAGAI PENGGANTI PRODUK KAYU
}

\author{
Harsi $^{1}$, Nasmi Herlina Sari ${ }^{2}$, Sinarep ${ }^{3}$ \\ 1,2,3 Jurusan Teknik Mesin Fakultas Teknik Universitas Mataram \\ JIn. Majapahit No.62 Mataram Nusa Tenggara Barat Kode Pos: 83125 \\ Telp. (0370) 636087; 636126; ext 128 Fax (0370) 636087
}

\begin{abstract}
Wood material is very popular in indonesia and all over the world, there are so many people who use it as their buildings contruction and also for their home tools, because the wood material is strong, long lasting, green living, save and lux. On the other hand the wood material will be mouldy if it meets water, thats why this material is not suitable to be placed in humid or wet places we need a new material that can be used as the subtitution of the wood material. The aim of this research is to know about how to make the composite of cotton/glass hybrid fiber and its mecanical using epoxy matrix, and then compare it with wood product. The wood product that used in this research is mahoni.

The composite making is using hand lay-up method and the variety fraction volume of cotton fiber and glass fiber are : 30\%:0\%, 25\%:5\%, 20\%: 10\%, 15\%:15\%, 10\%: $20 \%, 5 \%$ : $25 \%, 0 \%: 30 \%$, the epoxy matrix volume fraction is $70 \%$, where the orientasion of cotton fiber is rondom and $2 \mathrm{~cm}$ in lenght, whereas the orientasion of the glass fiber is equally with fiber lenght up to the lenght of mould. The researcher did some test they are: bending test that based on ASTM D 790 standart, compression test that based on ASTM D 695 standart.

The bending strenght's mean of all volume fraction's varieties of cotton/glass hybrid fiber composite shows the higher bending strenght than the bending strenght of mahoni which is used as the comparator. Afterwards the pressing strenght's mean of cotton/glass hybrid fiber composite especially in 20\%:10\% and 0\%:30\% fraction volume varieties, which is have the values orderly 37,74 $\mathrm{MPa}$ and $47,53 \mathrm{MPa}$, and it shows the higher pressing strenght than the pressing strenght of mahoni, it is $36,78 \mathrm{MPa}$. Based on the recearch that have been done we can conclude that the characteristic of mechamical cotton/glass hybrid fiber composite can be used as the (alternative) wood subtitution especially mahoni.
\end{abstract}

The key words ; Composite, cotton fiber, glass fiber, mahoni, bending strength, compression strenght, water absorbsing level.

\section{PENDAHULUAN}

Produk kayu merupakan produk yang sangat populer khususnya di Indonesia, terlihat pada banyaknya masyarakat yang masih memilih produk kayu sebagai material yang melengkapi tempat tinggalnya diataranya untuk membuat daun pintu, jendela dan perabot rumah lainya, dikarenakan sifatnya yang ramah lingkungan, aman dan terkesan mewah. Akan tetapi kelemahannya terletak pada sifat fisiknya yang begitu rentan lapuk jika terkena air, menyebabkan produk kayu tidak cocok di tempatkan pada bagian-bagian yang akan terkena lembab, contohnya saja pada pintu kamar mandi. Dan plastik maupun polimer sebagai produk pengganti memiliki harga yang cukup mahal yang terkadang masyarakat tidak mau membelinya. Untuk itu perlu adanya tindakan untuk mengatasi permasalahan tersebut, salah satunya dengan menciptakan sebuah produk baru yakni komposit hybrid dengan berpenguat serat kapas dan serat gelas yang nantinya akan bisa menggantikan produk kayu yang ada di pasaran saat sekarang ini.

Serat kapas merupakan tanaman yang banyak kita jumpai di berbagai daerah di indonesia, keberadaanya sangat mudah kita temukan di sekitar kita, petani banyak menamam tumbuhan ini di sawah-sawah mereka karena memiliki kegunaan yang sangat banyak dalam kehidupan sehari-hari, contoh kecil saja, masyarakat menggunakan serat kapas sebagai bahan untuk membuat benang pintal yang masih dikerjakan dengan manual untuk nantinya dijadikan sebagai kain tenun, serat kapas juga sangat besar mamafaatnya dalam bidang kesehatan antara lain digunakan sebagai pembersih luka atau sebagai bahan pembuat kain kasa untuk perban, dan masih banyak lagi kegunaanya yang lain. Tanaman kapas memiliki ketersediaan yang melimpah, mudah dibudidayakan kembali dan memiliki sifat fisik 
yang baik yakni mudah menyerap lembab dan melepaskanya kembali dengan cepat.

Dari uraian-uraian diatas maka ide untuk meneliti dan membuat matrial komposit hybrid serat kapas dan serat gelas sebagai pengganti produk kayu timbul dalam benak penulis.

Adapun permasalahan yang diangkat dalam penelitian ini adalah karakteristik sifat mekanik komposit serat hybrid kapas/gelas.

Agar permasalahan yang dibahas tidak melebar perlu diadakan pembatasan

masalah antara lain sebagai berikut :

1. Pengujian-pengujian yang dilakukan antara lain : uji bending, uji tekan dan uji penyerapan air.

2. Matrik yang digunakan adalah epoxy komposit.

3. Serat yang digunakan adalah serat kapas dan serat gelas.

4. Panjang serat gelas menyesuaikan dengan cetakan.

5. Orientasi serat kapas adalah acak, sedangkan serat gelas adalah searah.

6. Fraksi volume resin dengan serat adalah ; $70 \%$ : $30 \%$, dimana perbandingan serat kapas dengan serat gelas antara lain; 30\% : 0\%, 25\% : 5\%, 20\% : 10\%, 15\%: 15\%, 10\%: $20 \%, 5 \%: 25 \%, 0 \%: 30 \%$.

7. Tidak ada perlakuan yang diberikan pada serat pada penelitian ini karena, serat yang digunakan bukan serat yang langsung diambil dari alam, melainkan kapas kemasan yang banyak tersedia di pasaran dengan merk Modis Facial Cotton, yang tentunya sudah mengalami pemerosesan sebelumnya.

8. Digunakan kayu mahoni sebagai material pembanding dari komposit serat hybrid kapas/gelas ini .

Tujuan yang ingin dicapai dari penelitian ini yaitu, untuk mendapatkan bahan alternatif pengganti kayu yakni dengan membuat material baru yaitu material komposit serat hybrid kapas/gelas.

Manfaat yang ingin didapatkan dari penelitian ini antara lain :

1. Terciptanya sebuah material baru yang tersusun dari serat kapas, serat gelas dan matrik epoxy yang diharapkan menjadi sumber material alternative pengganti kayu.

2. Bagi peneliti adalah untuk menambah pengetahuan, wawasan dan pengalaman tentang penelitian material komposit.

3. Bagi akademik, penelitian ini dapat digunakan sebagai referensi tambahan untuk penelitian tentang material komposit baik serat alam maupun serat buatan.

\section{LANDASAN TEOR}

Penelitian tentang sifat fisis dan mekanis komposit serat kelapa-polyester dengan variasi panjang serat pada fraksi volume serat $30 \%$ didapatkan suatu kesimpulan bahwa semakin panjang serat yang digunakan kekuatan mekanis komposit semakin tinggi ${ }^{[1]}$

Hasil penelitan [2] tentang analisa pengaruh fraksi volume serat kelapa pada komposit matriks polyester terhadap kekuatan tarik, impact dan bending menunjukkan bahwa serat kelapa yang dikombinasikan dengan polyester sebagai matrik akan dapat menghasilkan komposit alternatif yang salah satunya berguna sebagai duduk bantal mobil, papan/meja. Dengan memvariasikan fraksi volume serat kelapa, diharapkan akan didapatkan kekuatan tarik, impact dan bending komposit yang maksimal untuk mendukung pemanfaatan komposit alternative.

Penelitia tentang pengaruh panjang serat terhadap kekuatan impak komposit enceng gondok dengan matriks poliester. Penelitian komposit diperkuat serat enceng gondok ini bertujuan mengetahui kekuatan tarik, kekuatan impak, kekuatan bending komposit serat enceng gondok dengan panjang $25 \mathrm{~mm}, 50 \mathrm{~mm}$ dan $100 \mathrm{~mm}$ dengan fraksi volume $80 \%$ matrik polyesterdan $20 \%$ serat enceng gondok. Dari hasil pengujian didapat harga kekuatan tarik tertinggi dimiliki oleh komposit dengan panjang serat $100 \mathrm{~mm}$ yaitu 11,02 $\mathrm{MPa}$, dengan modulus elastisitas 11023,33 MPa, Harga impak tertinggi dimiliki oleh komposit dengan panjang serat $50 \mathrm{~mm}$ yaitu $0,002344 \mathrm{j} / \mathrm{mm}^{2}$

Pengaruh perlakuan alkali terhadap sifat permukaan serat alam selulosa telah diteliti dimana kandungan optimum air mampu direduksi sehingga sifat alami hidrophilic serat dapat memberikan kekuatan ikatan interfacial dengan matrik polimer secara optimal (Bismarck, dkk, 2002).

Pengaruh perlakuan alkali $\mathrm{NaOH}$ pada serat alam selulosa menunjukkan peningkatan mutu permukaan serat dan sifat alami hydrophilic. Perlakuan alkali $8 \% \mathrm{NaOH}$ pada serat jute dapat mengubah tofografi permukaan serat dan struktur kristalnya ${ }^{[4]}$.

\section{Pengertian Komposit}

Didalam dunia industri kata komposit dalam pengertian bahan komposit berarti terdiri dari dua atau lebih bahan yang berbeda 
yang digabung atau dicampur menjadi satu. Menurut Kaw ${ }^{[5]}$ komposit adalah struktur material yang terdiri dari 2 kombinasi bahan atau lebih, yang dibentuk pada skala makroskopik dan menyatu secara fisika. Kata komposit dalam pengertian bahan komposit berarti terdiri dari dua atau lebih bahan yang berbeda yang digabung atau dicampur secara makroskopis. Sedangkan menurut Triyono dan Diharjo ${ }^{[6]}$ mengemukakan bahwa, kata komposit (composite) merupakan kata sifat yang berarti susunan atau gabungan. Composite berasal dari kata kerja "to compose" yang berarti menyusun atau menggabung. Jadi secara sederhana bahan komposit berarti bahan gabungan dari dua atau lebih bahan yang berlainan.

Salah satu keuntungan material komposit adalah kemampuan material tersebut untuk diarahkan sehingga kekuatannya dapat diatur hanya pada arah tertentu yang kita kehendaki, hal ini dinamakan "tailoring properties" dan ini adalah sifat istimewa komposit yaitu ringan, kuat, tidak terpengaruh korosi, dan mampu bersaing dengan logam, dengan tidak kehilangan karakteristik dan kekuatan mekanisnya.

Secara umum, dikenal tiga kelompok komposit :

1. Komposit berserat yaitu komposit berpenguat serat antara lain seperti, serat gelas (fiber glass), serat karbon, serat grafit sampai serat baja.

2. Komposit laminer atau laminat yaitu komposit berpenguat dalam bentuk lembaran seperti kertas, kain.

3. Komposit partikel atau partikulat yaitu komposit berpenguat dalam bentuk butiran seperti kerikil, pasir, filler dalam bentuk kontinyu.

Dalam hal polimer diperkuat serat, ada zat ketiga yang disebut zat penjodoh, penggabungan atau penyerasi untuk meningkatkan sekatan antara serat dan matrik $^{\lceil 7]}$

\section{Unsur Penyusun Komposit}

Pada umumnya bahan komposit terdiri dari dua unsur, yaitu serat (fiber) dan bahan pengikat serat (matrik).

\section{Serat}

Banyak jenis serat baik serat alam maupun serat sintetik. Serat alam yang utama adalah kapas, wol, sutra dan rami (hemp), sedangkan serat sintetik adalah rayon, polyester, akril, dan nilon.

Komposit dengan penguat serat (fibrous composite) sangat efektif, karena bahan dalam bentuk serat jauh lebih kuat dan kaku dibanding bahan yang sama dalam bentuk padat (bulk). Kekuatan serat terletak pada ukurannya yang sangat kecil, kadangkadang dalam orde mikron. Ukuran yang kecil tersebut menghilangkan cacat-cacat dan ketidaksempurnaan kristal yang biasa terdapat pada bahan berbentuk padatan besar, sehingga serat menyerupai kristal tunggal yang tanpa cacat, dengan demikian kekuatannya sangat besar.

\section{Matrik (Resin)}

Matrik atau resin dalam susunan komposit bertugas melindungi dan mengikat serat agar dapat bekerja dengan baik. Matrik harus bisa meneruskan beban dari luar ke serat. Umumnya matrik terbuat dari bahanbahan yang lunak dan liat. Polimer atau plastik merupakan bahan umum yang biasa digunakan. Matriks juga umumnya dipilih dari kemampuannya menahan panas.

Polyester, vinilester dan epoxy adalah bahan-bahan polimer yang sejak dahulu telah dipakai sebagai bahan matrik.

Persyaratan di bawah ini perlu dipenuhi sebagai bahan matrik untuk pencetakan bahan komposit :

1. Resin yang dipakai perlu memiliki viskositas rendah, dapat sesuai dengan bahan penguat dan permeable.

2. Dapat diukur pada temperatur kamar dalam waktu yang optimal.

3. Mempunyai penyusutan yang kecil pada pengawetan.

4. Memiliki kelengketan yang baik dengan bahan penguat

5. Mempunyai sifat baik dari bahan yang diawetkan.

Tidak ada bahan yang dapat memenuhi semua persyaratan di atas tetapi pada saat ini paling banyak dipakai adalah polyester tak jenuh ${ }^{[8]}$.

\section{Tipe Komposit Serat}

Untuk memperoleh komposit yang kuat harus dapat menempatkan serat dengan benar. Berdasarkan penempatannya terdapat beberapa tipe serat pada komposit, yaitu :

\section{Continuous Fiber Composite}

Continuous atau uni-directional, mempunyai susunan serat panjang dan lurus, membentuk lamina diantara matriknya. Jenis komposit ini paling sering digunakan. Tipe ini mempunyai kelemahan pada pemisahan antar lapisan. Hal ini dikarenakan kekuatan antar lapisan dipengaruhi oleh matriknya. 
2. Woven Fiber Composite (bi-dirtectional)

Komposit ini tidak mudah dipengaruhi pemisahan antar lapisan karena susunan seratnya juga mengikat antar lapisan. Akan tetapi susunan serat memanjangnya yang tidak begitu lurus mengakibatkan kekuatan dan kekakuan akan melemah.

\section{Discontinuous Fiber Composite}

Discontinuous Fiber Composite adalah tipe komposit dengan serat pendek, tipe ini dibedakan lagi menjadi $3^{\left[{ }^{[9]}\right.}$ :

a) Aligned discontinuous fiber

b) Off-axis aligned discontinuous fiber

c) Randomly oriented discontinuous fiber

Banyak penelitian menggunakan Randomly oriented discontinuous fiber merupakan komposit dengan serat pendek yang tersebar secara acak diantara matriknya. Tipe acak sering digunakan pada produksi dengan volume besar karena faktor biaya manufakturnya yang lebih murah. Kekurangan dari jenis serat acak adalah sifat mekanik yang masih dibawah dari penguatan dengan serat lurus pada jenis serat yang sama.

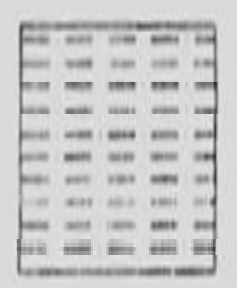

(a) Aligned

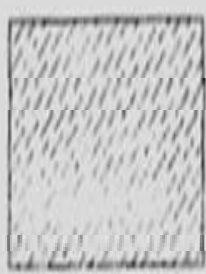

(b) Off-axis

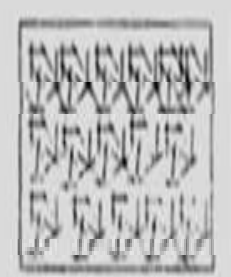

(c) Randomly Gambar 1. Tipe discontinuous fiber ${ }^{[9]}$

4. Hybrid Fiber Composite

Hybrid fiber composite merupakan komposit gabungan antara tipe serat lurus dengan serat acak. Tipe ini digunakan supaya dapat menganti kekurangan sifat dari kedua tipe dan dapat menggabungkan kelebihannya.

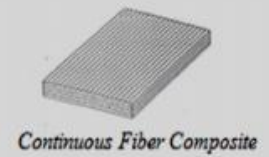

Continuous Fiber Composite

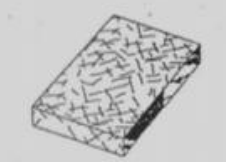

Randomly oriented discontinuous fiber Hybrid fiber composite Gambar 2. Tipe komposit serat

\section{Uji Bending}

Kekuatan bending suatu material dapat dihitung dengan persamaan berikut:

$$
\begin{aligned}
& \sigma_{\mathrm{b}}=\frac{M c}{I} \text {. } \\
& \text { Keterangan: } \\
& \sigma_{\mathrm{b}}=\text { Kekuatan Bending }(\mathrm{MPa}) \\
& \mathrm{M}=\operatorname{Momen}(\mathrm{Nmm}) \\
& I=\operatorname{Inersia}\left(\mathrm{mm}^{4}\right) \\
& \text { c = Jarak Dari Sumbu Netral Ke } \\
& \text { tegangan Serat }(\mathrm{mm})
\end{aligned}
$$

Pada material yang homogen pengujian batang sederhana dengan dua titik dudukan dan pembebanan pada tengah-tengah batang uji (three point bending), maka tegangan maksimum dapat dihitung dengan persamaan berikut

$\sigma_{b}=\frac{3 P L}{2 b d^{2}}$

Keterangan:

$\begin{array}{lll}\sigma_{b} & = & \text { Kekuatan Bending }(\mathrm{MPa}) \\ \mathrm{P} & = & \text { Beban }(\mathrm{N}) \\ \mathrm{L} & = & \text { Panjang Span }(\mathrm{mm}) \\ \mathrm{b} & = & \text { Lebar Batang Uji }(\mathrm{mm}) \\ \mathrm{d} & = & \text { Tebal batang uji }(\mathrm{mm})\end{array}$

\section{Uji Tekan}

Pengujian tekan dilakukan terhadap spesimen batang uji yang standar. Bahan yang akan diuji mula-mula dibuat menjadi batang uji dengan bentuk sesuai standar tertentu. Pada bagian tengah dari batang uji merupakan bagian yang menerima tegangan, pada bagian ini diukur panjang batang uji, yaitu bagian yang dianggap menerima pengaruh pembenanan.

Beberapa persamaan dalam uji tekan :

$\sigma_{T}=\frac{P}{A_{o}}$

Dimana :

$\sigma_{T}=$ tegangan tekan $\left(\mathrm{kg} / \mathrm{mm}^{2}\right)$

$\mathrm{P}=$ beban tekan $(\mathrm{kg})$

$\mathrm{A}_{o}=$ luas penampang mula-mula $\left(\mathrm{mm}^{2}\right)$

$\varepsilon=\frac{l_{1}-l_{0}}{l_{0}}$

Dimana :

$I_{1}=$ panjang setelah dibebani $(\mathrm{mm})$

$I_{0}=$ panjang mula-mula sebelum dibebani (mm)

\section{Proses Pembuatan Komposit dengan Menggunakan Epoxy}

a. Persiapan alat dan bahan.

b. Pengolesan kit mobil sebagai pelumas secara merata pada cetakan, untuk memudahkan mengeluarkan komposit dari cetakan. 
c. Tuangkan epoxy sesuai takaran perhitungan dengan gelas ukur kedalam gelas pencampur.

d. Masukkan serat kapas kedalam epoxy yang telah kita siapkan, aduk hingga tercampur merata.

e. Masukkan campuran epoxy dengan kapas kedalam cetakan kira-kira setengah takaran dari volume komposit yang akan dibuat.

f. Masukkan serat gelas yang telah disiapkan dengan orientasi searah atau memanjang pada cetakan, atur sedemikian rupa agar seratnya lurus dan tersebar pada cetakan dengan jarak yang sama.

g. Setelah itu tuangkan kembali setengah takaran campuran epoxy dengan kapas diatas permukaan serat gelas sampai tertutupi semua.

h. Penutupan dengan menggunakan kaca yang bertujuan agar void yang terlihat dapat diminimalkan jumlahnya yang kemudian dilakukan pengepresan dengan menggunakan batu penekan.

i. Proses pengeringan, proses ini dilakukan sampai benar-benar kering yaitu 2 hari dan apabila masih belum benar-benar kering maka proses pengeringan dapat dilakukan lebih lama.

j. Proses pengambilan komposit dari cetakan yaitu menggunakan pisau ataupun cutter.

k. Finising, menghaluskan permukaan komposit dengan menggunakan gergaji dan gerinda tangan.

\section{Standar Spesimen Bahan Uji Komposit}

\section{Standar Spesimen Bahan Uji Bending}

\section{Komposit}

Bentuk spesimen pengujian kekuatan bending yang digunakan pada penelitian ini mengacu pada standar uji ASTM D 790 dengan dimensi $(152 \times 25,4 \times 6) \mathrm{cm}$. Bisa dilihat pada gambar 4 disamping.

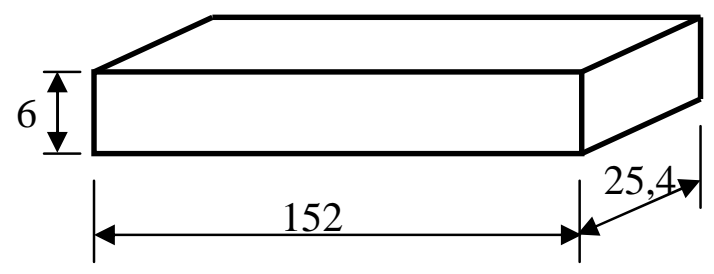

Gambar 4. Spesimen uji bending ASTM D 790

\section{Standar Spesimen Bahan Uji Tekan Komposit}

Standar uji yang digunakan yaitu bentuk spesimen uji tekan berdasarkan standar ASTM D695. Bentuk dan ukuran Spesimen uji dapat dilihat pada gambar 5 berikut:
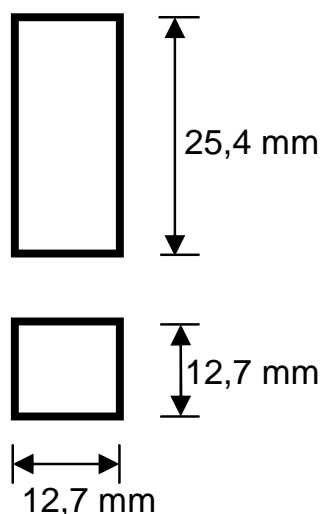

Gambar 5 Spesimen uji tekan ASTM D695-96

\section{HASIL PENGUJIAN DAN PEMBAHASAN Hasil pengujian Bending Komposit}

Dari data yang telah didapatkan menunjukkan nilai rata-rata kekuatan bending masing-masing variasi, dari data tersebut juga diperoleh hubungan antara kekuatan bending dengan variasi fraksi volume serat seperti terlihat dalam gambar 7 disamping.

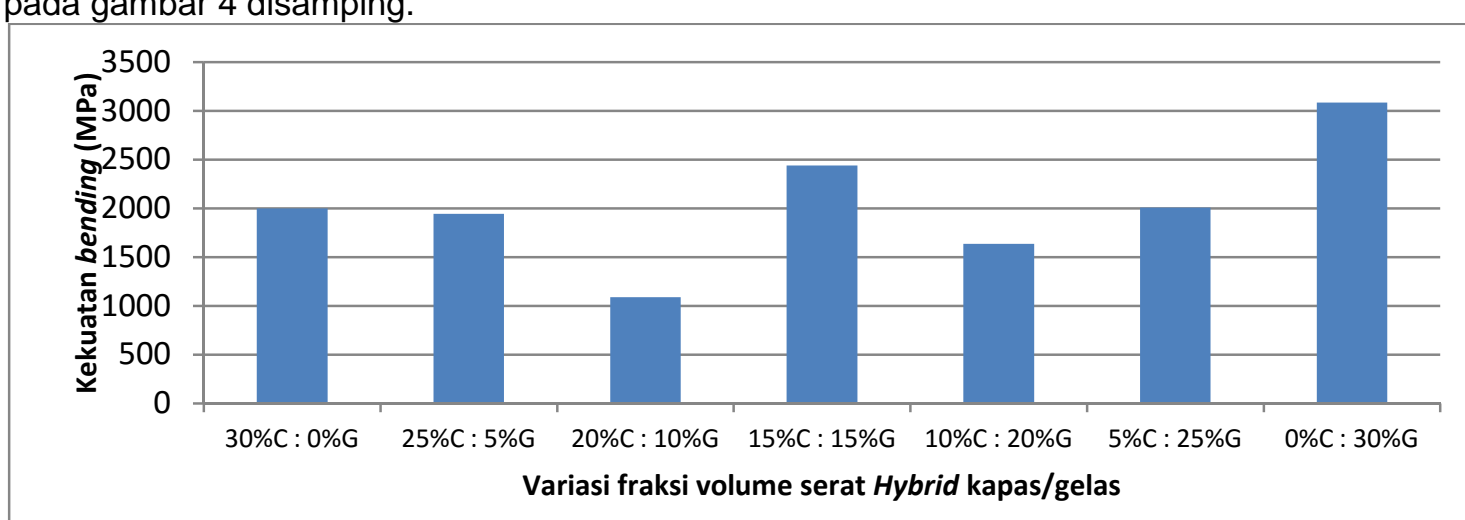

Gambar 7. Hubungan antara variasi fraksi volume serat dengan kekuatan bending komposit 
Dari gambar 7 menunjukkan bahwa variasi harga kekuatan bending komposit serat hybrid kapas/gelas dipengaruhi oleh persentase serat yang terdapat pada komposit tersebut.

Gambar 7 juga menunjukkan bahwa harga kekuatan bending rata-rata tertinggi ditunjukkan oleh komposit serat hybrid kapas/gelas 0:30 (\% volume) sebesar $3081,52 \mathrm{MPa}$, dibanding pada komposit serat hybrid kapas gelas 30:0, 25:5, 20:10, 15:15, 10:20, 5:25, (\% volume) yakni dengan harga berturut-turut sebesar; 1998.53, 1943.56, 1089.25, 2439.24, 1636.36, 2008,5 (MPa). Dan harga kekuatan bending rata-rata terendah ditunjukkan oleh komposit serat hybrid kapas/gelas 20:10 (\% volume) yakni sebesar 1089.25 Mpa.
Dari data kekuatan bending komposit yang telah dilakukan, bahwa harga kekuatan bending semua variasi fraksi volume komposit serat hybrid kapas/gelas, memiliki harga kekuatan bending yang jauh lebih tinggi bila dibandingkan dengan harga kekuatan bending sampel kayu mahoni yang dalam hal ini digunakan sebagai pembanding yang hanya memiliki kekuatan bending sebesar $127 \mathrm{MPa}$ saja.

\section{Hasil Pengujian Tekan Komposit}

Dari data yang telah didapatkan dibuat grafik hubungan antara variasi volume serat dengan kekuatan rata-rata yang ditunjukkan pada gambar 8 dibawah.

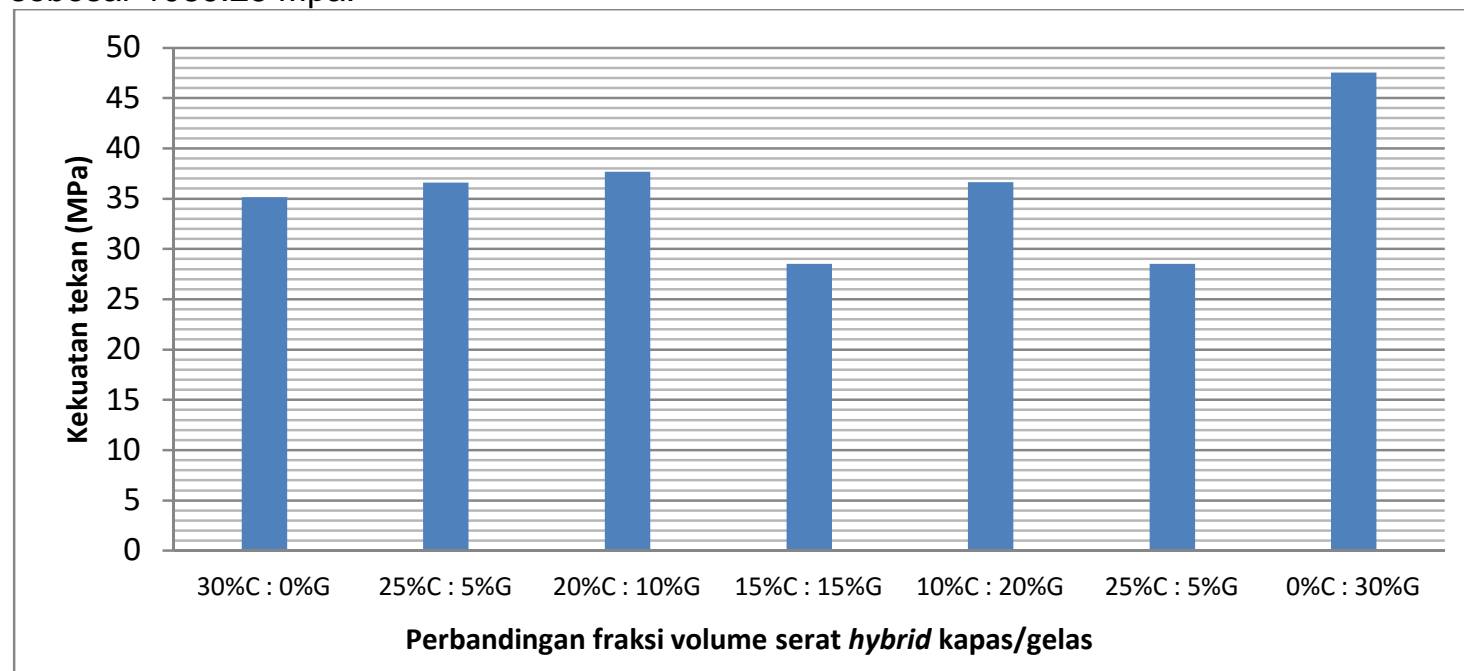

Gambar 8. Hubungan antara variasi fraksi volume serat dengan kekuatan tekan komposit

Dari gambar 8 diatas dapat dilihat bahwa harga kekuatan tekan rata-rata komposit serat hybrid kapas/gelas dengan fraksi volume berturut-turut yakni: 30\%:0\%, $25 \%: 5 \%$ dan $20 \%: 10 \%$, nilainya semakin tinggi yaitu berturut-turut sebesar 35,26 Mpa, 36,51 Mpa, 37,74 Mpa. Kemudian mengalami penurunan kekuatan tekan rata-rata pada fraksi volume serat $15 \%: 15 \%$ yaitu sebesar 28,52 Mpa, pada fraksi volume serat 10\%:20\% terjadi kenaikan kekuatan rata-rata yaitu sebesar 36,64 Mpa, dan pada fraksi volume serat $25 \%: 5 \%$ terjadi penurunan kekuatan kembali yaitu sebesar $28,51 \mathrm{Mpa}$ dan terakhir fraksi volume serat 30\%:0\% terjadi lonjakan kekuatan yaitu sebesar 47,53 Mpa.

Dapat diketahui dari grafik bahwa harga kekuatan tekan rata-rata komposit serat hybrid kapas/gelas tertinggi dimiliki oleh komposit dengan variasi fraksi volume serat
$0 \%: 30 \%$ yaitu dengan kekuatan rata-rata tekan sebesar 47,53 Mpa.

Dari data uji kekuatan tekan yang didapatkan, menunjukkan bahwa harga kekuatan tekan rata-rata komposit serat hybrid kapas/gelas khususnya pada variasi fraksi volume $20 \%$ : $10 \%$ dan $0 \%$ : $30 \%$ yakni dengan harga berturut-turut sebesar 37,74 $\mathrm{MPa}$ dan 47,53 MPa, disini menunjukkan harga kekuatan tekan yang lebih tinggi bila dibandingkan dengan harga kekuatan tekan dari sampel kayu mahoni yang digunakan sebagai pembanding yaitu sebesar 36,78 $\mathrm{MPa}$.

\section{KESIMPULAN}

Dari beberapa pengujian yang telah dilakukan sebelumnya terhadap komposit serat hybrid kapas/gelas, dimana pengujianpengujian tersebut antara lain; penguujian bending dan pengujian tekan, dapat disimpulkan sebagai berikut: 
1. Harga kekuatan bending rata-rata semua variasi fraksi volume komposit serat hybrid kapas/gelas, memiliki harga kekuatan bending yang jauh lebih tinggi bila dibandingkan dengan harga kekuatan bending sampel kayu mahoni yang dalam hal ini digunakan sebagai pembanding.

2. Harga kekuatan tekan rata-rata komposit serat hybrid kapas/gelas khususnya pada variasi fraksi volume $20 \%: 10 \%$ dan 0\%:30\% yakni dengan harga berturut-turut sebesar 37,74 MPa dan 47,53 MPa, disini menunjukkan harga kekuatan tekan yang lebih tinggi bila dibandingkan dengan harga kekuatan tekan dari sampel kayu mahoni yang di gunakan sebagai pembanding yaitu sebesar $36,78 \mathrm{MPa}$.

Berdasarkan uraian diatas dapat ditarik kesimpulan bahwa karakteristik sifat mekanik dari komposit serat hybrid kapas/gelas ini bisa digunakan sebagai bahan alternatif pengagganti kayu, khususnya kayu mahoni.

\section{SARAN}

Berdasarkan penelitian yang telah dilakukan maka beberapa saran dapat diberikan guna penelitian selanjutnya yaitu:

1. Dalam pembuatan spesimen uji komposit hybrid ini, pengaturan seratnya harus benar-benar diperhatikan, membutuhkan ketelitian agar penyebaran seratnya merata pada tiap bagian komposit, baik pada serat orientasi acaknya maupun searah untuk mendapatkan hasil yang baik,

2. pencampuran resin dengan kapas yang homogen sangat sulit didapatkan dalam pembuatan komposit ini, sebaiknya fraksi volume untuk resin tidak kurang dari $70 \%$.

3. Sebaiknya pengujian dilakukan dengan menggunakan mesin yang sama atau alat uji yang memiliki ketelitian yang sama, agar hasil yang didapatkan bagus.

\section{DAFTAR PUSTAKA}

[1] Kamal, zainul (2008) tugas akhir sifat fisis dan mekanis komposit serat kelapa polyester dengan variasi panjang serat pada fraksi volume serat $30 \%$. Skripsi thesis, universitas Muhammadiyah Surakarta.

[2] Sulistijono, 2008, Analisa Pengaruh Fraksi Volume Serat Kelapa Pada Komposit Matriks Polyester Terhadap Kekuatan Tarik, Impact Dan Bending. ITS Semarang.

[3] Purboputro, Pramoko , I, 2005, Pengaruh Panjang Serat Terhadap Kekuatan Impak Komposit Enceng Gondok Dengan Matrik Polyester, Jurusan Teknik Mesin, Universitas Muhamadiah Surakarta, Kartasura.

[4] Eichorn, dkk, 2001, Review Current International Research into Cellulosic Fibres and Composites, Journal of Polymer, Volume 37, No 24, Gret Brittain.

[5] Kaw, autar, k, 1997, Mechanics of komposite materiall autar, k. Kaw.--2nd ed. P.cm.--(mechanical engineering;v.29).

[6] Triono ,T dan Diharjo, K, 1999, Material Teknik, Buku Pegangan Kuliah, UNS Press, Surakarta.

[7] Feldman, D, dan Hatomo, J.A, 1995, Bahan Polimer Konstruksi Bangunan, Gramedia Pustaka Utama.

[8] Surdia, T, 2000, Pengetahuan Bahan Teknik, Jakarta: Pradnya Paramita.

[9] Gibson, F.R., 1994, "Principles of Composite material Mechanis", International Edition", McGraw-Hill Inc, New York. 